\title{
CONCRETIONS AND THEIR GEOLOGICAL EFFECTS
}

BY J. E. TODD

(Read before the Society January 1, 1908)

CONTENTS

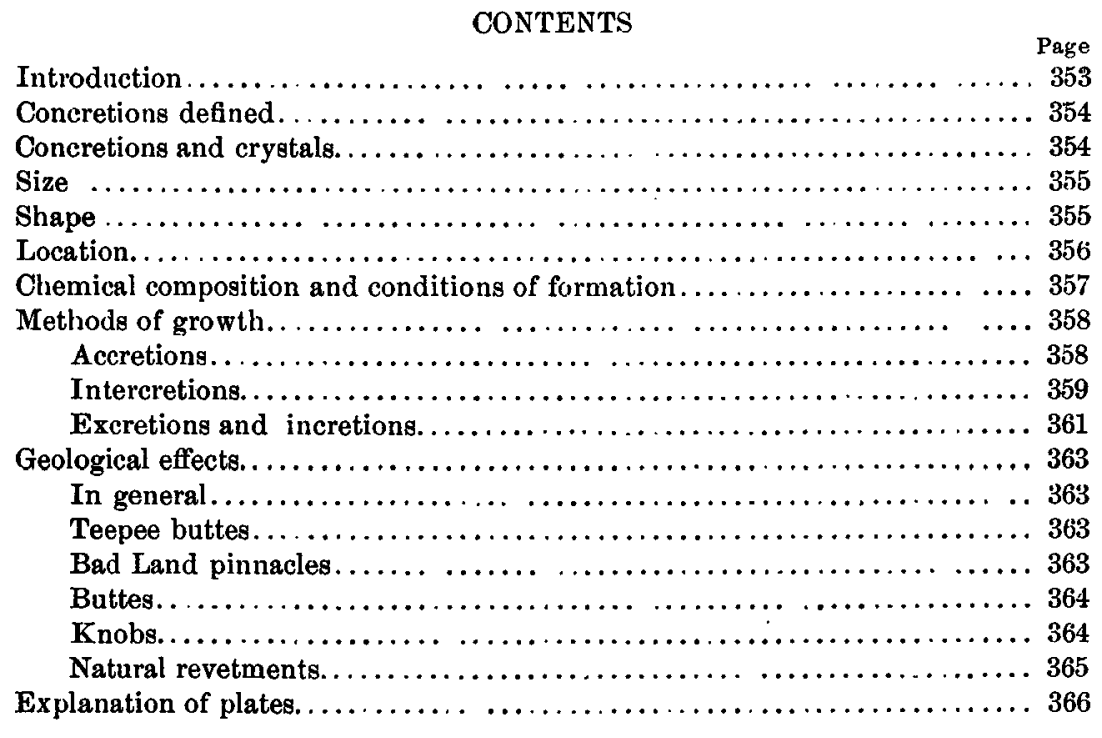

\section{INTRODUCTION}

Some over thirty years ago the writer's attention was turned to the peculiar cracked concretions abounding in loess, which are known as loess kindchen. Not satisfied with current explanations of their origin and history, he has ever since improved opportunities to note and collect concretions, which abound in vast numbers and of numerous types in the Mesozoic and Cenozoic formations of the west. This paper presents some of the more prominent conclusions for consideration and criticism. Some well known facts are briefly recapitulated for the proper setting forth of the more novel conclusions.

It should be stated at the outset that the author disclaims intimate acquaintance with the chemical aspects of the subject. His data are 
mainly observational, not experimental, and his discussion physical and not to any considerable degree chemical. Literature on the subject is meager. Some writers comment on the subject as quite obscure.*

\section{Concrettons Defined}

Concretions are stones that grow, or, in other words, are nodular growths of various minerals sparsely distributed through the country rock. They vary greatly in size, shape, composition, distribution, and method of growth.

They should be distinguished from secretions, which may sometimes resemble them in form and structure. Such growths are formed in cavities, and the outer layers are the older instead of the younger, as is commonly the case in concretions. Geodes may be considered as imperfectly filled secretions. Though often externally resembling concretions they differ from most of the latter by being hollow, and from those concretions which are cracked within, by having a simple cavity bounded by a shell of nearly equal thickness throughout.

Concretions differ from stalactites, either pendant or coralloidal, which are formed in the former case by trickling water, and in the latter case by oozing water; they also differ from stalagmites which result from dropping water; and from other forms of cave deposits, as these are all found with free surfaces and not embedded, as is always the case with concretions. Moreover, though all grow mainly by additions to the outside, like concretions, and though portions of them may resemble concretions in form, yet they are alway's attached by a base to country rock, which is never true of concretions.

\section{Concretions and Crystals}

Crystals are the normal form which minerals take when solidifying from solution or fusion without the interference of surrounding material or contact with each other. Concretions result when the embedding rock prevents the orderly arrangement of the molecules, though they may still cohere in an irregular way. Evidence for this conception is found in the numerous gradations observed between the typical extreme cases. This is shown by numbers $8-10$ and $17-21$, plate 49 , and numbers 5 and 7 , plate 50 .

\footnotetext{
* Furthermore, the discussion is limited to structures formed from aquenus solution and does not treat to any considerable extent of those formed through the medium of liquids of fusion. Quite possibly similar physical relations may oceur in both, and consequently sometimes processes and structures appear in the latter case similar to those we describe in aqueous deposits. Iithophysæ and other concretionary structures found in igneous rocks would seem to corroborate such a view, but we have not had opportunity to study such forms.
} 
From what has been said the inference is easy that crystals form where the collection of molecules takes place in an open space, or a space occupied only by liquids, while concretions grow embedded in the country rock. This is true in general, but there are some exceptions. Crystals like garnet, tourmaline, etc., form apparently in rock excluding the surrounding grains, while calcite frequently forms crystals including grains of sand naturally lying within their limits.

The force conceived to bring together molecules into either crystals or concretions is a form of molecular attraction, influenced perhaps, sometimes, by electrical relations. This attraction withdraws molecules from the mother liquor in the immediate vicinity of the crystal and builds them into its structure. This impoverishes the solution in contact, and consequently diffusion takes place from the saturated solution farther away to enrich it. As these processes continue, quasi-currents of molecules similar in nature to those of the crystal converge toward it from all directions and from an indefinite distance. It is not necessary to postulate motion of the liquid which acts as a vehicle, though motion of such medium may sometimes accelerate or otherwise influence the growth of both crystals and concretions. The impoverishing of the surrounding country rock in the vicinity of concretions is often conspicuously indicated by a difference of color.

\section{Size}

Concretions vary greatly in size, some being microscopic and others attaining several yards in diameter. As in the case of crystals, the size of concretions is probably inversely as the rapidity of their formation. Another limiting factor may be the strength of solution from which they form.

\section{SHAPE}

When concretions form in a massive deposit where the circulation is equal in all directions, the usual shape is globular. This is often beautifully exhibited in sandstone. It has been observed particularly in those of the Fox hills and Laramie formations. The latter case is recorded in the names of the Cannon Ball river and the Pomme Blanche hills of North Dakota. Such are found also in the marls and loams of the Miocene and Pleistocene. When formed in shaly formations, as noted long ago, the shape is usually more or less lenticular, because accumalation goes on more rapidly in the plane of stratification than at right angles to it. If shales are very impervious the concretions may be disklike, as in figure $22 d$, plate 49 , and figure 3 , plate 50 , or even sometimes 
ring-like. When these various forms are near enough to coalesce, very complex and often surprisingly imitative forms appear-tubers, riveted plate, and grotesque imitations of fruits, roots, parts of animals, or various utensils. These are frequently collected in amateur museums. When large they may be looked upon as of almost miraculous origin and become objects of superstition.

In loams, especially in connection with root marks, as explained later, concretions are often vertically elongated, so as to resemble tubers and fusiform roots. Again, some concretions, for some reason not yet satisfactorily explained, are very much elongated horizontally. In the Laramie formation they attain size and shape fitly described as log-like (see plate 51, figure 1). They have been found over 100 feet in length, counting the divisions separated by cross-joints. The detached sections not infrequently closely resemble in shape, size, and color saw-logs stripped of their bark. It has been suggested that they have formed around organic matter collected in furrows on the beaches of lakes.* This opinion is strengthened by their often occurring parallel with one another, and sometimes so near as to coalesce, as in plate 51, figure 2. Moreover, those on about the same level have been observed to lie in systems, extending for many rods, or even miles, perhaps, in broadly sinuous lines, like a lake shore.

\section{LOCATION}

Concretions, like crystals, seem to owe their location to predetermining circumstances. In the case of the latter a particle of similar substance accidentally present seems to act as a starting point or nucleus. A particle of precipitating agent may also act in a similar way. Bones, leaves, shells, etcetera, are found embedded by the concretions which have formed around them; but where no such nuclei are present the precipitating mineral tends to concentrate itself at nearly equidistant intervals. If the precipitating influence is at high temperature and progressing rapidly, we may expect these centers will be nearer together and the resulting concretions smaller.

The foregoing remarks apply to spaces fully submerged in ground water or far removed from the surface of ground water. It is probable, however, as will appear from consideration given in a subsequent section, that the surface of the ground water, or water-table, is preeminently a zone of concretionary growths. There the various precipitating influences are especially active, and by the fluctuations of the surface of the ground water this action is internittent, which fact sumetimes increases

*J. E. Todd : Ameriean Geologist, vol. xvii, 1896, p. 347. 
its efficiency, as will be seen later. Concretions also form around openings, particularly around root marks or tubules, by which more direct connection is kept open with the outer atmosphere. This is particularly true of what we have described further on as incretions.

\section{Chemical Composition and Conditions of Formation}

As already hinted, concretions are rarely pure or composed of any one mineral, but almost always include more or less of the rocks in which they grow. Almost any soluble mineral may take concretionary form if only evaporation or cooling gradually reduces the solution below the point of saturation. Of course, only those which are nearly or quite insoluble under ordinary circumstances will form permanent concretions. The more common concretions are therefore those formed by chemical reactions which produce insoluble minerals from soluble.

Doubtless calcareous concretions-that is, those composed of calcium carbonate-are the most abundant, for carbonate of lime is every where, and carbonic acid, its solvent, is quite as common. Moreover, the conditions are frequent for its evaporation and the formation of carbonate of lime, which is nearly insoluble in common waters.

In quite a similar way carbonate of iron, or siderite, forms concretions of clay ironstone, which are very common in certain strata. Another quite common concretionary mineral is iron pyrites. It is hard as steel, and its concretions of much size are formidable hindrances to the welldriller. Fortunately they are commonly thin and brittle. Ferric sulphate reduced by carbon in organic compounds becomes $\mathrm{FeS}_{2}$, and possibly also ferrous carbonate acted upon by hydrogen sulphide produces the same compound.

Silica even may be gathered in concretions from an alkaline solution or from a solution of alkaline silicate through reaction with carbonate of lime. Several of these processes are not fully understood, and the above statements are not to be taken as results of careful experimentation, but as generally expressed probable reactions, strengthened in some cases by corroborating observations.

Another cause of precipitation quite different from most of the others is the easy combination of oxygen with a ferrous compound, like ferrous carbonate and ferrous sulphate, and probably also organic salts, by which an insoluble ferric hydroxide is formed. This is particularly influential in forming ferric concretions of the incretion and excretion types.

"The following is a table of chemical reactions probably producing concretions : 


Solutions of-
$\mathrm{CaCO}_{3}, \mathrm{H}_{2} \mathrm{CO}_{3}$
$\mathrm{FeCO}_{3}, \mathrm{H}_{2} \mathrm{CO}_{3}$
"
"“
$\mathrm{FeSO}_{4}$
"
$\mathrm{Na}_{2} \mathrm{SiO}_{3}$
Any substance

Evaporation of $\mathrm{CO}_{2}$
"
Action of $\mathrm{H}_{2} \mathrm{~S}$
" " $\mathrm{CO}_{2}$
" " $\mathrm{CaCO}_{3}$
" oxygen
" "
" organic matter
Drying or cooling

\section{Meinods of Growth}

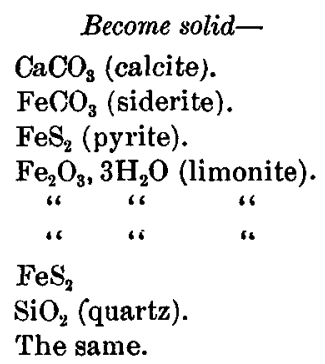

\section{ACCRETIONS}

The common conception of the growth of a concretion, as is perhaps suggested by the name, is that particles are gathered together toward the center so as to produce growth regularly and steadily from the center outward. Such may be aptly called an accretion. Such accretions, from the nature of the case, will be solid and include or enmesh particles of the rock in which they form without any considerable disturbance of them. It is conceivable that the molecular attraction between the molecules of the concrescent minerals may be so strong as to exclude foreign particles to some extent, but evidence of such action has not been often observed. That carbonate of lime is not likely to do so with common sand, seems attested by the occasional formation of regular calcite crystals with true angles and planes in sand, which include the sand grains lying within the space of the crystal without any trace of exclusion. As crystal growth is without doubt by simple accretion, it follows easily that calcareous accretions will not exclude sand, even if they may some other foreign particles, and it seems probable that other concretion forming minerals act in a similar way in similar circumstances.

Simple accretions in stratified material preserve the stratification in their substance. Accretions may also have a radiate structure, which may be due to the development of a modified crystalline structure. They may probably also show rhythmical or concentrically banded structure as in figure 12, plate 49 . This is not certainly known but probable. It may be due to conditions corresponding to those which form specter and concentrically stratified crystals-that is, to intermittent periods of deposisition with possible-counter influences between, or to the intermittent deposition of impurities or of some coloring matter.

While it can not be questioned that they are normally solid, it is conceivable that sometimes a wet mass of calcium hydrate or of calcareous 
clay may act as a nucleus, and after the formation of a more rigid shell that subsequent shrinking by drying may produce a cracked interior, as Professor Dana and other writers have stated. The writer, after considerable study and observation, is not aware of any clear proof of such a case. In all concretions observed the cracked portion has not been of such a character, but of similar composition to that of the rest of the concretion.

\section{INTERCRETIONS}

On the contrary, from a study of such growths we have been led to quite a different explanation for those showing a cracked interior. Instead of the interior shrinking after the outside has become rigid, on the contrary the outside or outer portion has expanded and become too large for the interior, and it has done so with sufficient force to wrench apart the interior. Moreover, this has been a gradual process, the growing zone passing gradually outward by contemporaneous accretion. 'The cracks starting first in the central portion gradually follow the growing zone outward. This process is theoretically shown in figures $3 a-e$, plate 49. To simplify the case, a globular form is assumed, but a lenticular shape. similar to figure 4, is more common in the Cretaceous shale of Dakota, and vertically elongated ones or rudely globular are more common in loess, as in figures 5 and $22 a$. In the Benton and Pierre clays they grow to a size of several feet, sometimes a rod or more in extent. They are cracked into polygonal blocks 3 or 4 inches across. The evidence in favor of the conclusion stated above may be given as follows:

1. The cracking can not be due to drying, because (a) the material is not clayey, but usually contains much sand, and is not distinguishable from the outer portion of the concretion; (b) because the concretions are sometimes found by well diggers to be filled with water, and from this fact, as well as from their shape, they are called "jugs." Moreover, the crevices are often lined with crystals or filled with crystalline matter. In the latter case the structure is known as a septarium. Such facts show that the interior was saturated with water probably during all the time of its formation. If the shrinkage was due to desiccation, why should not the material when wet again recover its former bulk and the cracks disappear?

2. Nor can it be confidently referred to contraction from cementation. It is difficult to believe that this can explain the amount of shrinking indicated in the figures, though we may frankly admit our ignorance of any quantitative evidence concerning the amount of shrinkage due to molecular cohesion.

3. Nor can we conceive of any chemical reaction producing such loss of volume. 
4. The more positive evidence of our view is shown in figures $17, a, b, e$, and 22 of plate 50 . Compare also figure 5 , plate 49 , where it is clearly shown that the origin of the concretion is complex; that it has been built by successive additions in the order indicated, and each has shown the same tendency to crack in the interior. In this case the theory of shrinking by drying must be dismissed at once, for it would require not only moisture succeeding drouth repeatedly, but in some way local concentration of moisture and of argillaceous material deposited again and again without any obvious reason. If it be suggested that in some way the shrunken portions were all moist or of peculiar shrinkable nature at the same time, we must explain the more difficult point of seeming succession of crescentic members overlapping one another. We must explain also the still more significant fact that in every case the cracks are broadest toward the center of the whole mass, not toward the center of each member, as we should expect if they were all formed contemporaneously.

5. Another evidence of our view are the signs which sometimes appear around these concretions of their crowding the surrounding strata. In the Benton and Pierre shales a rude, cone-in-cone structure is often developed around them. Again, in the 'litanotherium beds, silicious concretions are found to have split the fossil bones in which they form.

6. Another argument may be derived from the analogous behavior of films on evaporating solutions and also in the tendency of crusts around the edge of a liquid to blister up and crack off from the vessel containing them.

The following is a more detailed statement of the process :

First, the collection of similar molecules as in an accretion; but conditions are such that the solidification takes place not entirely on the surface but largely between the particles already deposited, wedging them apart with force sufficient to separate the portion inside the expanding zone, and also to resist and force outward the embedding strata. This may result mainly from the fact that the outer portions have the first chance to appropriate incoming material. It may be thought incredible that molecular cohesion is powerful enough to do this, but when we think of its force when resisting tension it may help us somewhat to understand when it manifests itself apparently in an opposite direction. We say apparently, for really in both cases it is the attraction of molecule for molecule, and the apparent diverse effects are due simply to the different mechanical relations. Indeed, when we think how capillary action may force molecules of water into the pores of wood with sufficient power to split rocks in the quarry, and freezing water has still greater power, it may not be so difficult to believe that 
calcareous particles by intercretion may accomplish the results under consideration.

It should be noted further that the first cracking of the interior takes place when the breadth of the growing zone is several times that of the ruptured interior, and that the cracks gradually spread toward the surface as the concretion increases in size by surface accretion. The intercretionary action may in later stages even extend the cracks quite to the surface. This may be made more evident by the study of figures 23 and 16 , plate 50.

The compound concretion in figure $\mathbf{1 7}$ may be plausibly explained by simply supposing several successive periods of growth corresponding perhaps to as many rises of ground water so as to submerge it more or less completely. The marked cessations in growth which divide the successive portions may have been due to the effects of weathering or oxidation while it was not completely covered by the ground water.

\section{EXCRETIONS AND INCRETIONS}

Another method of formation of concretionary nodules is so different that it may be questioned whether it should be classed with the rest under the head of concretions. It is the form which Dana has called "centripetal" concretions.* He applied the term to signify the fact that the final or permanent growth is toward the center. It follows, therefore, that they are not as compact as other concretions, and that the material must first be concentrated either by previous accretion or by unusually concentrated sedimentation. The mineral most frequently showing this action is ferric hydroxide. Ferrous salts dissolving are oxidized to ferric hydroxide when they come in contact with the air on the surface of the containing rock, as in figure $16 a$, plate 49 . Such action appears often in ferruginous sandstones and limestones. Such cases can hardly be called concretions. Certain forms of spheroidal weathering, especially those where successive concentric shells of iron oxide are formed, may be explained in this way. Similar action with similar resulting structure, on a smaller scale, may be found within the rock around some moist spot as figures $16 b, c$. In such a case the results resemble accretions of a rhythmical structure.

These excretions are frequently hollow. This form is simpler and we therefore consider it first. If an accretion or intercretion of ferrous carbonate like figure 14, either pure or mingled with clay or sand, be reached by water charged with carbon dioxide and oxygen, it will begin to dissolve, and the iron will be precipitated on its surface as ferric hydroxide. The impurity will remain undisturbed. Figure 14 shows

. Manual of Geology, fourth edition, p. 98.

LI-BULL. GroL. Soc. Am., Vor.. 14, 1902 
the stages in this process. $a$ is the original intercretion, $b$ an intermediate stage when the forming shell is separated from the undissolved remnant by a leached zone of the impurity left behind. A photograph of such a stage is shown in figure 13 , plate 50 . It will be noticed that the oxide forms in the joints of the cracked concretion as well as on the surface. The finished product is represented by $c$, when the cavity of the hollow iron pebble has been opened and the incoherent impurity rattled out. Such may be found in weathered sand and sandstone.

But the form most pertinent to our subject is the nodular form with rhythmical structure, which may resemble certain forms of accretion. This rhythmical structure Dana, with his customary insight, recognized as analogous to the concentric rings formed by a drying emulsion like milk upon a flat surface. We may suppose a similar rhythmical action of forces in both cases. In the emulsion the drying accumulates a film of the precipitated particles where the drying is most active, namely, on the outermost edge. When the liquid loses volume, so that it can no longer fill that limit, it is withdrawn by cohesive attraction considerably within the first limit, where it again stands and deposits a nother ring till there is a similar necessity of withdrawing again, so that the process is repeated indefinitely. In the case of a concretion, however, we must suppose a vibration between the different influences, for we can not have a volume of the liquid playing against a cushion of air because of the geometrical relations and the inelasticity of water; but we can suppose either an alternating action between carbonic acid and oxygen in the water as the water gradually withdraws by drying, or we may suppose by varying volumes of water corresponding to different showers or other fluctuations of climate. The writer has not seen good examples of this structure, but concentric color lines in weathered rocks are so often found that there seems no good reason for doubting concretionary action of this sort.

There are, moreover, structures resembling those just described, except that the practical surface is a cavity communicating with the outer air. The more common example may be found around root marks, which may be so much coarser than the pores of the surrounding deposits that they may be emptied of water while the latter are still saturated. Hence they form around these root marks concentric cylindrical films of iron oxide having a vertical length equal to the difference in height between the top of the ground water in the root marks and that in the surrounding deposit. Moreover, as these levels fluctuate, these elongated concretions may have greater vertical length. Such concretions of minute form are very common in the loess. A diagram of such is shown in figure 15 , plate 49 . They are often of minute rhythmical structure, but frequently are nearly solid except the small hole in the center. 
Their usual size and shape resemble quite closely a common lead-pencil. Their method of growth, as given above, is a matter of inference rather than positive observation. If those described in the earlier part of this section may be properly called excretions, because the particles move outward to their final deposition, then these may for a similar reason be called incretions; but neither term is wholly satisfactory.

Incretions are often found in the loess composed also of carbonate of lime. They are often like clay pipe stems in form and size. Moreover, they may at certain levels increase by accretion or intercretions into nodules of considerable size, resembling tuberous roots in form and in relation to the stem-like concretions, as is shown in figure $22 a$, plate 49. Such tuber-like enlargements seem more likely to occur near levels where the top of the ground water stands for some time.

\section{Geological Efreecrs}

\section{IN GENERAL}

Concretions may be considered as a kind of local cementation of unconsolidated strata, and therefore may merge gradually into wholly consolidated strata, which are well known to form the controlling factors of topography. Hence we are prepared to believe, on general principles, that concretions themselves may be very influential in topography.

\section{TEEPEE BUTTES}

This striking feature in certain localities on the western plains was ingeniously traced by $\mathrm{Mr}$ G. K. Gilbert some years ago to concretions cementing together colonies of Lucina occidentalis.* All gradations may be pointed out along a certain horizon of the Pierre formation from the sharp, conical knoll to the low mound with the concretions scattered about on the surface. Near the trail between Deadwood and Bismarck the axis of one of these buttes stands completely uncovered in the form of three or four huge boulder-like concretions, each of many tons weight, resting one on another, as though giant hands had piled them there. The relations of these concretions to the teepee buttes is clearly shown in figure 23 , plate 49 .

\section{BAD LAND PINNACLES}

The scenery of the White River bad lands has been long noted for its grotesque and picturesque features. Pinnacles, castellated shapes, pyramids, pillars, spires, etcetera, are found in unlimited numbers. The prevalent deposit is a sandy marl, traversed with irregular strata of sand and gravel. Both in the marl and in the sand many flat concretions have 
been formed. In some cases they merge into one another and form continuous strata, but more frequently they are more or less detached. Under the influence of erosion the latter become the caps of earth pillars which may sometimes rise several feet in height. As the process of erosion goes on rapidly these stand out at different levels on the steep slopes, sometimes as detached pinnacles and at other times as buttresses receding in steps one above another.

Similar effects are found in the dark colored clays and loams of the Laramie which comprises much of the Little Missouri " bad lands."

\section{BUTTES}

Studding the plain west of the Missouri in the Dakotas are many isolated buttes which stand out as conspicuous landmarks. They are carved from the Laramie and Fox Hills formations. They remind one of the pinnacles just described on a grander scale. They sometimes rise to 100 or 200 feet in height and may have an area at the top of an acre or more. With a little study one discovers that their tops are approximately on a level, and that this level farther west becomes embodied in a tableland of greater or less extent. The common explanation of these features is that at some time a stratum of sandstone, which is frequently found capping the buttes, formerly extended over the whole region, and that the buttes are the simple results of circumdenudation. Further study, however, reveals the fact that some of the buttes, especially those of the Fox hills. are not capped by continuous sandstone strata, but by layers of more or less separate concretions lying in a bed of sand or loam. In other cases, where the formation is Laramie, while the butte may be capped by a heavy stratum of sandstone in some cases, in other cases only concretions are found. sometimes of gigantic size. It seems, therefore, probable that instead of the sand stratum having been consolidated over the whole region it has been consolidated only locally in concretions which have merged into one another so as to form the stratum capping the first mentioned form, and in other cases they have not become so merged, although they have been near enough together to efficiently resist erosion: hence we may believe that the buttes owe their existence to local consolidation of strata in the concretionary form. This view is strengthened by finding that in the regions farther west, where erosion has not. worked so actively, the tableland is capped by a sand stratum, with the consolidation locally developed in the way described. Figures 25 and 27, plate 49 , illustrate this theory.

\section{KNOBS}

Another topographical effect, and rather more common than the last mentioned, is the formation of knobs of more or less rounded form. In 
the last case mentioned a later stage, following the flat top butte, is where erosion has displaced the concretions and left them strewn over the summits and sides of a rounded knob. Such may result therefore where the concretions are largely restricted to one stratum.

More commonly, however, they are distributed through several strata and with more or less uniform prominence. For example, they may occur as lenticular concretions in a bed of shale or in the limestone in the form of flint nodules. In the former case the result follows the washing away of the embedding shale, in the latter case where the limestone becomes dissolved and leaves the concretions resting in a stratum of residuary clay. The form of the concretion has much to do with its efficiency in this respect. Those which are globular are quite apt to roll down the slope and leave the summit unprotected, but in the case of lenticular forms they are apt to keep their position and form a very effective covering. If the concretions crack into angular fragments they become especially efficient in protecting the surface. 'This is apt to be the case of chert nodules, which have produced the knobs of central Tennessee and southeastern Missouri. Similarly, the large calcareous concretions of the Pierre in Dakota break into angular fragments, so that sometimes a single large concretion may furnish capping for a quite conspicuous knob.

In the case of globular concretions there may be a tendency to form knobs in a secondary stage as follows: In an early stage of erosion they may roll down the sides of a ravine and accumulate in the bends of the watercourse at the bottom. As erosion continues, these bends resist the erosion of the water, which is therefore turned aside, and in the process of ages the general surface of the country is lowered below the level of the accumulation first formed, and it may stand conspicuous as a knob. Action similar to this has been frequently noticed on the sides of the deep valleys carved out of easily eroded material, with stone deposited either in the clays, as in the case of boulder-clay, or where the stony material rests on the top, as the capping of a terrace. Examples of this sort have been noticed in the hillsides of the Missouri valley where it cuts through the Pierre shales overlaid by the terraces and till of the glacial period. No cases can be quoted where concretions have been the sole cause of such action.

\section{NATURAL REVETMENTS}

Under this head we may include cases where the concretions have accumulated at the foot of cut banks and steeper slopes bounding rivers and lakes, as in figure 26 , plate 49 , and figure 2, plate 50 . From what has been said in the last section, it may be readily seen that a stream cutting a 
bank abounding in concretions will soon have a quantity of them interfering with the further action of its waters. The same may be true also where lakes and the ocean cut against deposits of similar character. Hence concretions have an important effect in limiting the size of lakes and the encroachment of the sea, and they also have much to do with the features of river valleys. A stream cutting through rocky strata of uniform hardness naturally produces canyons bounded by cliffs. In softer strata of uniform character similar features may appear at first, but very soon give way to gentle slopes. In other words, the stream reaches grade easily and swiftly. The effect of concretions is intermediate between these two forms. The upper part of the slopes may cut back to a gentle angle, and yet the stream becomes limited to a more definite channel than in the second case, so that the bottom is not widened, although the valley may be open. Moreover, the stream is not likely to ever have much of a flood plain. Where streams pass through a stratum of concretion-bearing clays with similar soft deposits barren of concretions above and below, there is apt to be a narrower valley and a steeper slope in the concretion-bearing region.

These are some of the more obvious results of a study which, if continued with diligence and discrimination, promises to reveal still more impressively the influence of concretionary action upon physiography and the general history of the earth's surface.

\section{Explanation of Plates}

\section{Plate 49.-Concretions, their Structure and Effects}

Figure . 1.-A secretion.

FIGURE 2.-A geode.

FIGURE 3.-An intercretion, showing stages of growth by sections through one of globular form.

Figure 4.--Sections through a lenticular intercretion. $a$, vertical; $b$, horizuntal. When the cracks are filled with mineral it becomes a septarium.

Figure 5.-Section through a compound intercretion like numbers 17 and 22 , plate 50 .

Frgure 6.-An accretion with nucleus.

Fiaure 7.-A cavern, showing stalactites, $a$, formed by trickling water, and $b$, by seeping water, and $c$, stalagmite, all accretionary growths but not concretions.

FIGURE 8. -Theoretical diagram of an isometric molecule, showing axes or bonds. 


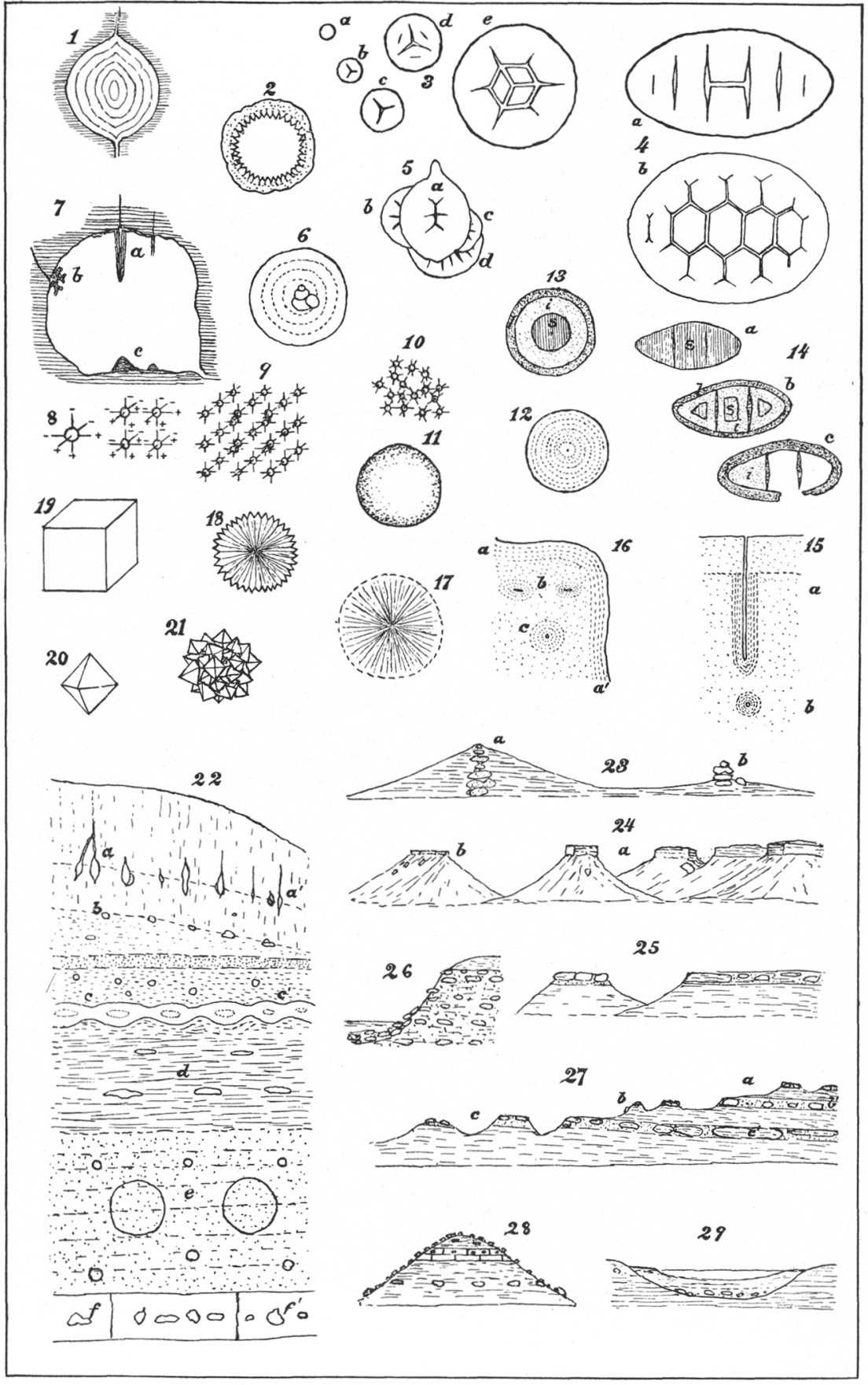


Figuri 9. - Such molecules arranged in a crystal like number 19.

Figure 10. - Such molecules irregularly arranged, as in a concretion.

Figure 11.-External view of a concretion like number 12.

Figure 12.-A globular concretion, showing concentric rhythmical structure.

Figure 13.-An excretion, or centripetal concretion, in which iron oxide is transferred from the interior, $s$ (siderite), to the exterior, $l$ (limonite), leaving behind impurity, $i$, as in number 13 , plate 50 .

FIGURe 14.-A siderite intercretion, $b$, the same changing to $c$; $c$, the same with siderite dissolved, forming a "hollow pebble" broken on one side so that the impurity is discharged from two chambers.

Frave 15.-An incretion forming around a rootmark-a, vertical section; $b$, a horizontal.

FIGURE 16.-Excretionary action forming ferruginous shells next the surface of a ferruginous sandstone, $a-a$, and also embedded excretions, $b$ and $c$.

FIGUR: 17. A globular concretion showing radiate structure.

Figure 18.-Similar, showing crystalline facets on the surface.

Fraukes 19 and 20.-Cubic and octahedral crystals.

Fraure 21. -A cluster of octahedral crystals.

FIgURE 22.-An ideal section showing forms of concretions, according to character of embedding formation- $a$, loess kindchen, starting as incretions, afterward becoming accretions along the water-table, some of them compound; $b$, irregular nodules in loamy clay; $c-c$, concretions merging into one another, as in many cases including those figured in plate $51 ; a-d$, lenticular form in shale; $e$, globular forms in massive sandstone; irregular chert, in limestone.

Figure 23.-Concretions including Lucina occidentalis, causing a teepee butte- $a$; $b$, the uncovered core.

Figure 24.-Buttes caused by a stratum of sandstone.

FIGURE 25.-Similar buttes formed by concretions locally abounding in a stratum of sand.

Figure 26.-Concretions forming a revetment by a lake or river.

Figure 27.-A more comprehensive view of buttes passing into mesas where erosion has not been so active or where concretions have become more extensive or more numerous.

Fraure 28.-A knob caused by concretions from different strata.

Frguke 29. Formation of clay-iron-stone concretions in the sediment of a pond. Eventually by long erosion this may form a knob. 


\section{Plate 50.-Various Concretions}

Figures 1 and 2.-Concretions from river sand.

Figure 3.-Concretion from shale.

Figures 6 and 12.-Concretions of various forms and composition, all accretions.

FIGUREs 7 and 10. -Barite, with radiate structure.

Fraures 6 and 9.-From shale with fern leaf nucleus.

Figure 8.-A compound concretion from sandstone.

Figure 13.-An "excretion" showing the siderite nucleus (compare numbers 13 and 14, plate 49).

Frguras 14 and 15.-Pyrite and calcareous concretions formed around ammonite shells.

Figure 16.-An intercretion showing cracked interior with cracks partly filled with calcite.

FiguRE 17. - A compound intercretion, opened to show different members.

Figure 18.-Reptilian vertebra serving as a nucleus for calcareous concretion.

Fiaures 19, 20 and 21.-Quartz geodes.

Fiaure 22.-Number 17, with the different members in position.

Fraure 23.-A nother intercretion, like 16; both are from Benton shales.

\section{Plate 51.-Log-like Concretions}

Figura 1.-Log-like concretions in Laramie beds, near Camp Crook, South Dakota.

Figure 2. Similar concretions coalescing laterally on North fork of Grand river, South Dakota.

\section{Plate 52.-Concretion Horizon and Natural Revelment}

FigURe 1.-Concretion horizon in the Laramie, near the junction of Flint Rock creek and Moreau river.

Fiavra 2.-Natural revetment formed of concretions from the Laramie, on shore of lake in northern Dewey county, South Dakota.

\section{Platra 53.-Concretions in' Wyoming}

Figure 1.-Concretions in Fox Hills sand, near Cooper creek, Wyoming.

Figure 2.-Lenticular concretion showing sand erosion, from the same formation, near Rock creek, Wyoming. 


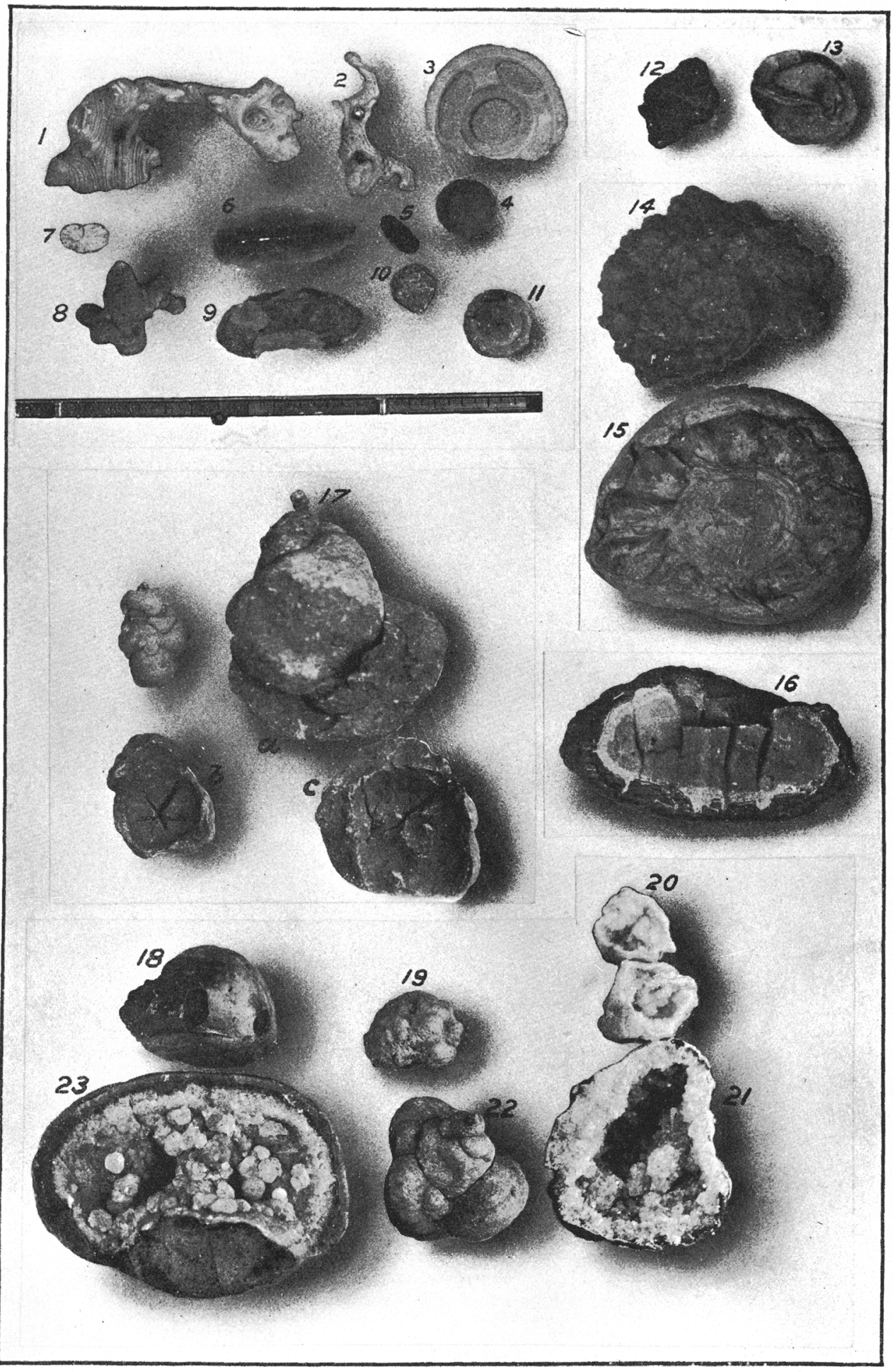




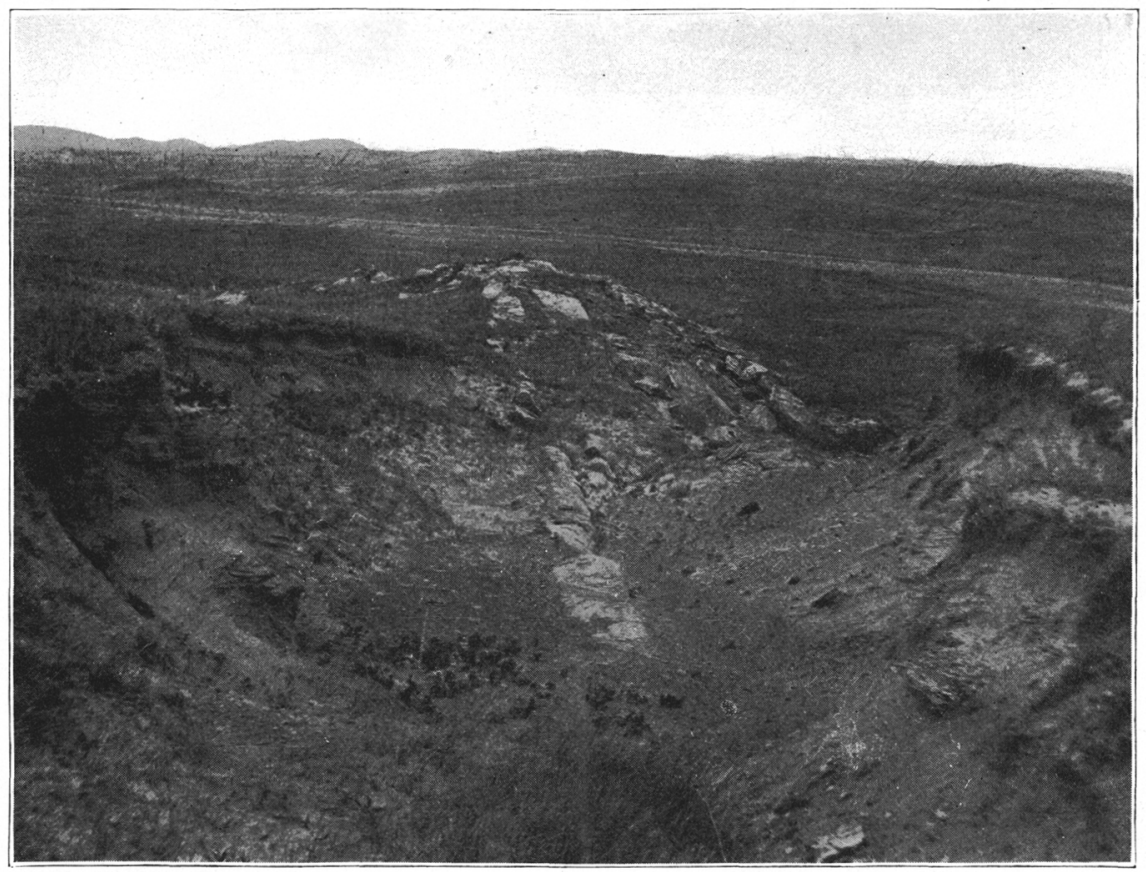

Figure 1.-Log-hike Concretions in Laramie Beid

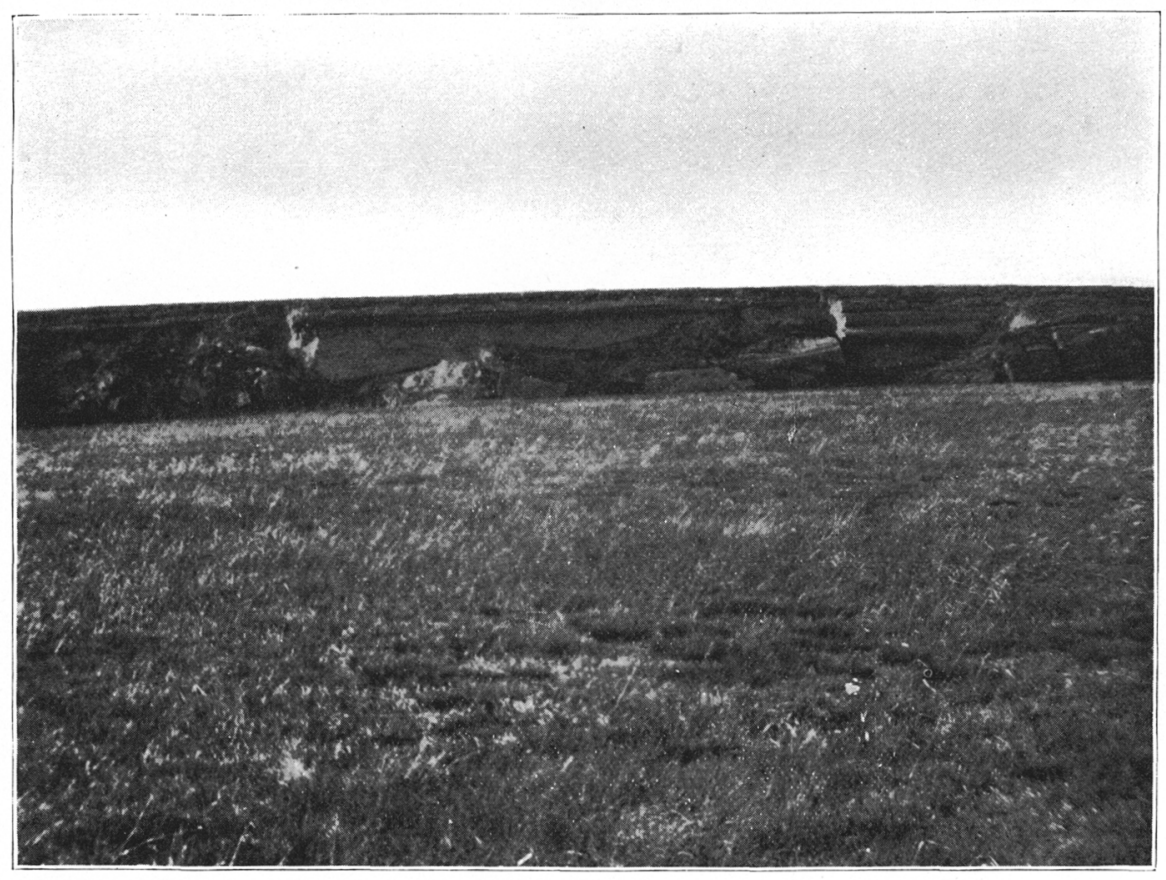

Figure 2.-Log-tike CONCRETIONS 


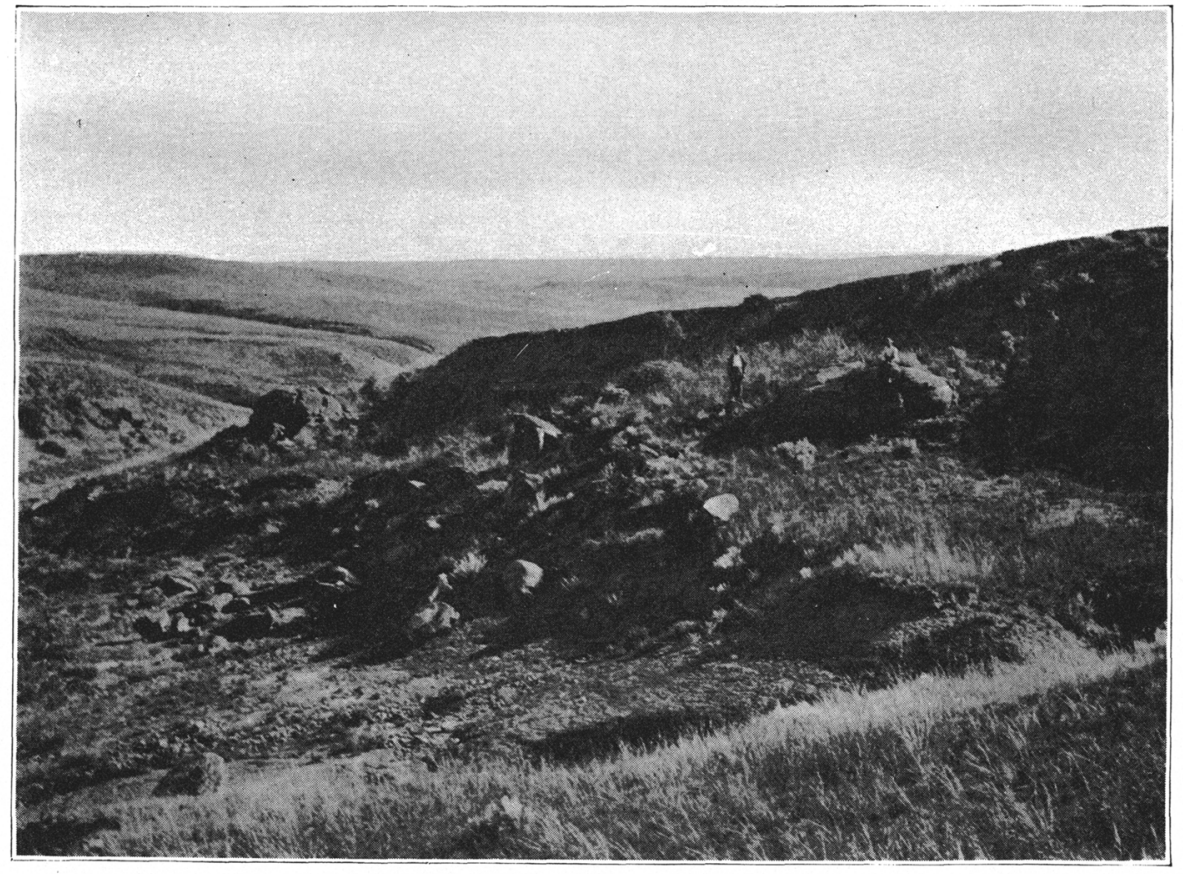

Figure 1,-Concretion Horizon in the Laramie

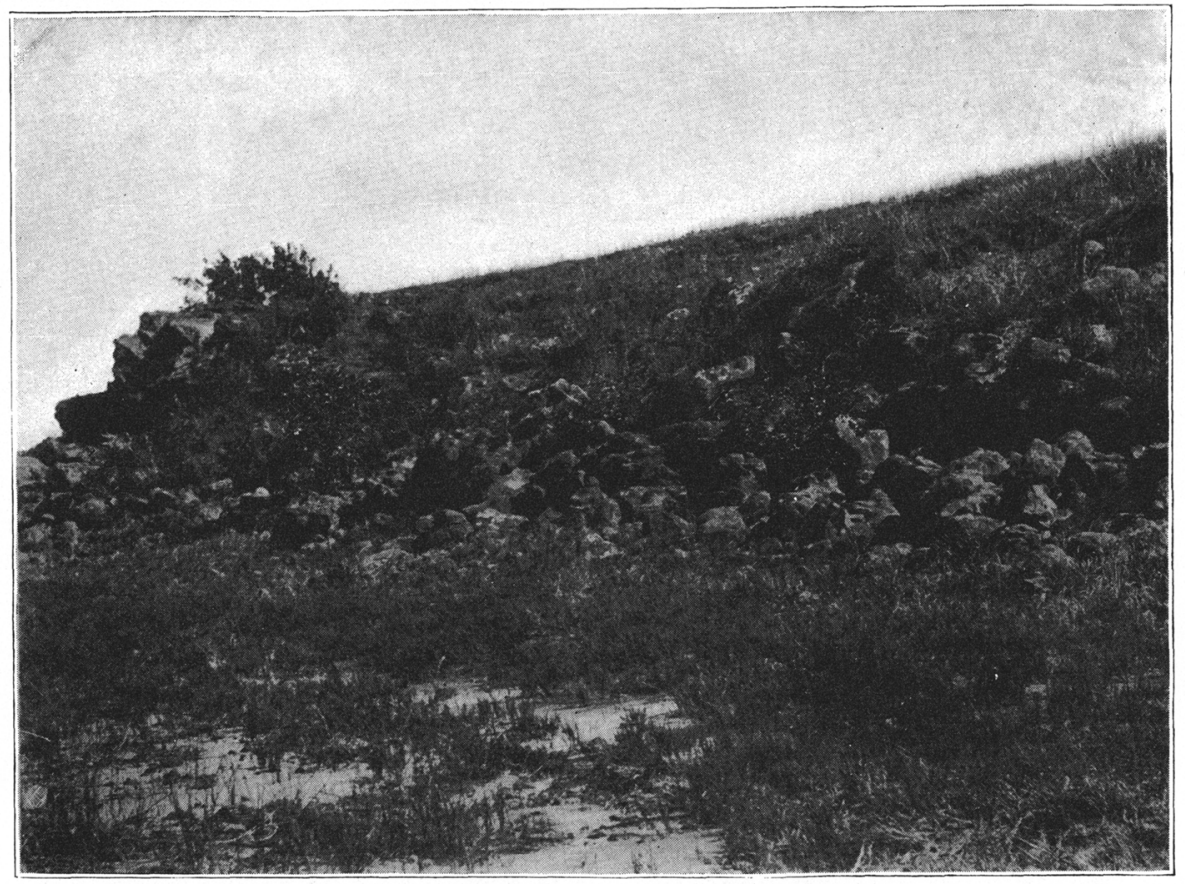

Figure 2.-Nát'ural Revetiment 


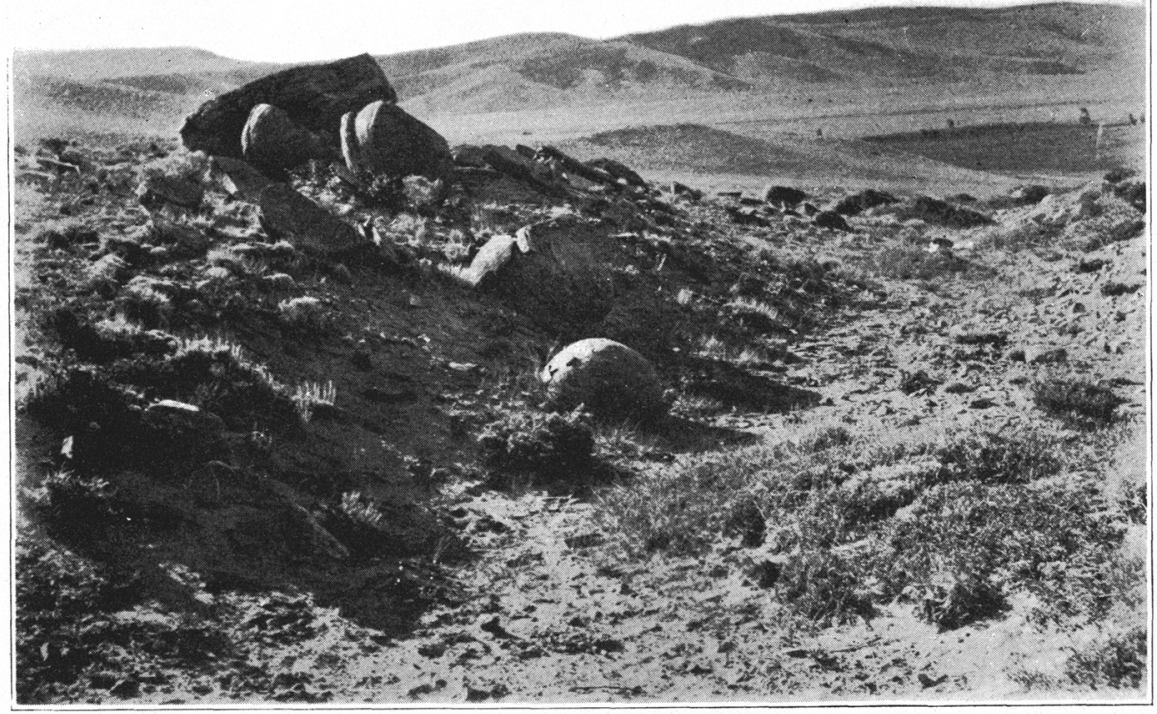

Figure 1.-Concretions in the Fox Hillis

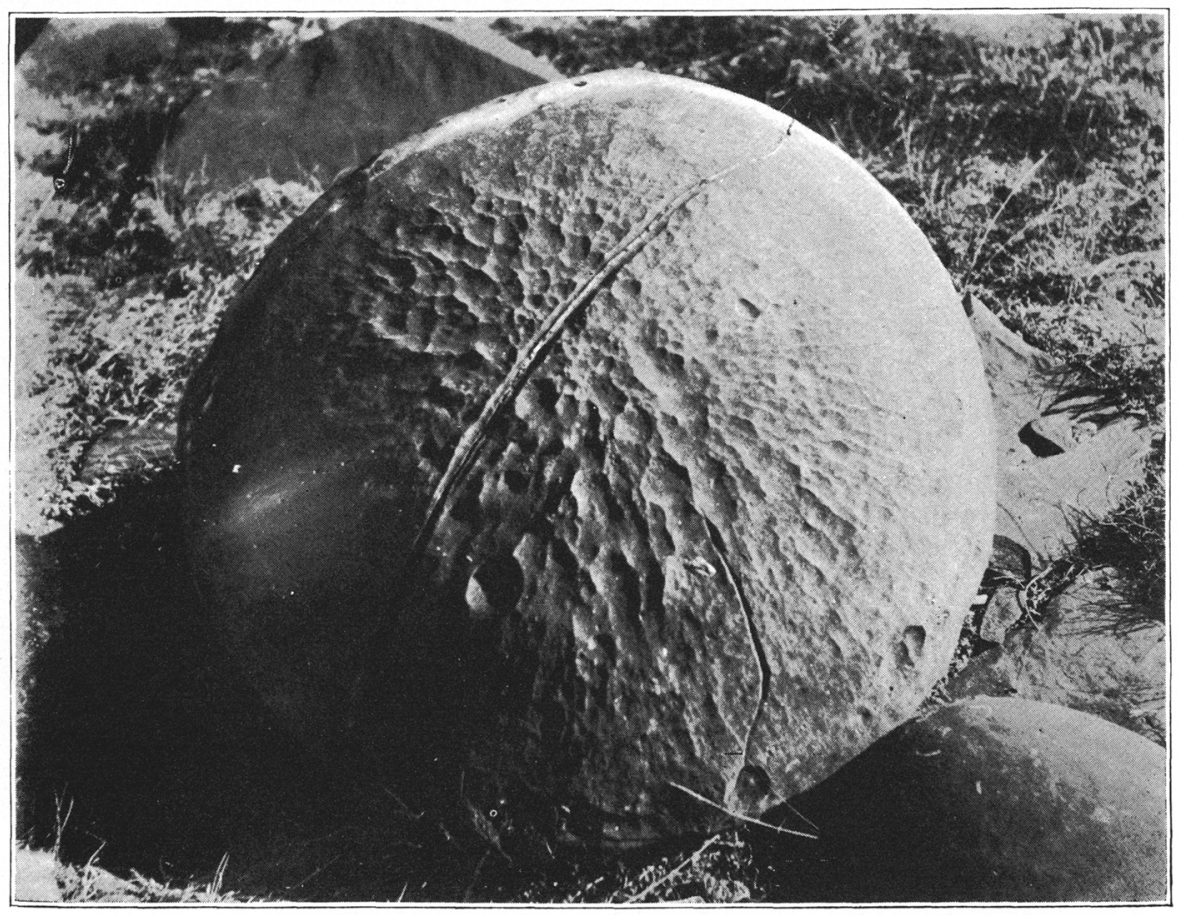

Figure 2.-Concretions showing Sand Erosion 